\title{
Medievalista
}

Online

$22 \mid 2017$

Número 22

\section{Johnni Langer (org.), Dicionário de mitologia nórdica: símbolos, mitos e ritos}

Leandro Vilar Oliveira

\section{OpenEdition}

1 Journals

\section{Edição electrónica}

URL: http://journals.openedition.org/medievalista/1387

DOI: 10.4000/medievalista.1387

ISSN: 1646-740X

\section{Editora}

Instituto de Estudos Medievais - FCSH-UNL

\section{Refêrencia eletrónica}

Leandro Vilar Oliveira, " Johnni Langer (org.), Dicionário de mitologia nórdica: símbolos, mitos e ritos », Medievalista [Online], 22 | 2017, posto online no dia 01 dezembro 2017, consultado o 23 setembro 2020. URL : http://journals.openedition.org/medievalista/1387 ; DOI : https://doi.org/10.4000/ medievalista.1387

\section{(c) (i) (8)}

Mediavalista está licenciado com uma Licença Creative Commons - Atribuição-NãoComercial 4.0 Internacional 
Título / Title: Recensão: LANGER, Johnni (org.) - Dicionário de mitologia nórdica: símbolos, mitos e ritos. São Paulo: Hedra, 2015 (581 pp.)

Autor(es) / Author(s): Leandro Vilar Oliveira

Universidade / University: Universidade Federal da Paraíba (UFPB)

Faculdade e Departamento / Unidade de Investigação - Faculty and Department /

Research Center: Centro de Educação (CE) - Programa de Pós-graduação em Ciências das Religiões (PPGCR)

Código Postal / Postcode: 58031-220

Cidade / City: João Pessoa

País / Country: Brasil

Email Institucional / Institutional email: vilarleandro@hotmail.com

Fonte: Medievalista [Em linha]. Direc. Bernardo Vasconcelos e Sousa. Lisboa: IEM.

Disponível em:

http://www2.fcsh.unl.pt/iem/medievalista/MEDIEVALISTA22/oliveira2211.html

ISSN: 1646-740X

Data de recepção do texto / Received for publication: 19 de Novembro de 2016 


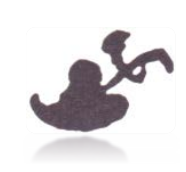

\section{Recensão: LANGER, J ohnni (org.) - Dicionário de mitologia nórdica: símbolos, mitos e ritos. São Paulo: Hedra, 2015 (581 pp.)}

\section{Leandro Vilar Oliveira}

$\mathrm{Na}$ academia brasileira os estudos relacionados com a mitologia greco-romana ainda predominam, principalmente nos cursos de Letras Clássicas, Ciências das Religiões e História, sendo seguidos por estudos relacionados com a religiosidade e mitologia egípcia e celta. Todavia, nos últimos dez anos, vêm estando em voga e crescendo de forma promissora os estudos medievalistas que trabalham a história, cultura, sociedade e mitologia dos escandinavos ${ }^{1}$.

Se há dez anos os trabalhos sobre vikings e a mitologia nórdica eram pontuais no Brasil, sendo realizados por poucos estudiosos, hoje dispomos de um número regular de teses, dissertações e monografias, essencialmente publicados nos últimos quatro anos ${ }^{2}$. No que diz respeito aos artigos e trabalhos de comunicação, estes vem crescendo consideravelmente ao ponto de haver já eventos específicos, como o caso da realização do Colóquio de Estudos Vikings e Escandinavos (CEVE), que ocorre anualmente, desde 2012, na Universidade Federal da Paraíba (UFPB), consistindo no maior evento acadêmico dessa área em território brasileiro, promovido pelo Núcleo de Estudos Vikings e Escandinavos (NEVE).

Até o ano de 2015, havia dois dicionários de mitologia nórdica em língua portuguesa publicados no Brasil. Um deles, intitulado Dicionário de Mitologia Nórdica ${ }^{3}$, foi publicado na década de 1960 por Owen Ranieri Mussolin (sob o pseudônimo de

\footnotetext{
${ }^{1}$ LANGER, Johnni - "Uma breve historiografia dos estudos brasileiros de religião nórdica medieval”. Horizonte, Belo Horizonte, v. 14, 43 (Julho - Setembro 2016), pp. 919-923.

${ }^{2}$ LANGER, Johnni - “Uma breve historiografia...”, pp. 924-932.

${ }^{3}$ ESOPINHO - Dicionário de Mitologia Nórdica. Belo Horizonte: Editora Enigmística Moderna, s.d.
} 
Esopinho), tratando-se de “uma obra de popularização”. Posteriormente, na década de 1970, assistiu-se ao lançamento do Dicionário de Mitologias Européias e Orientais $(1973)^{4}$, que dedicava um capítulo a abordar a mitologia germânica (termo usado à época para se referir à mitologia nórdica também). Ambos os dicionários foram produzidos por autores que desconheciam mais profundamente o tema, sendo obras que basicamente descreviam ou narravam os mitos, sem apresentar análise ou comentários a respeito da mitologia, da cultura, da sociedade e dos estudos da Era Viking (VIII-XI), período no qual estes mitos estiveram em grande destaque. A principal proposta destes dicionários era a de apresentar a um público amplo as referidas narrativas.

Dispomos hoje de um novo dicionário, o primeiro produzido por especialistas da área que possuem doutorado ou mestrado no tema. É, além disso, uma obra pioneira, na medida em que é um dos poucos livros em língua portuguesa a realizar uma análise geral sobre a mitologia nórdica. Intitulado Dicionário de mitologia nórdica: símbolos, ritos e mitos, publicado pela Editora Hedra no ano de 2015, o dicionário é organizado por Johnni Langer, um dos principais estudiosos sobre a Era Viking e a Escandinávia no Brasil, e um dos fundadores do Núcleo de Estudos Vikings e Escandinavos (NEVE). Uma obra que nos chega num momento propício e num cenário fértil para tais estudos.

O dicionário contou com a participação de vinte e dois estudiosos de origem brasileira, alguns dos quais formados em universidades no exterior, sendo a maioria historiadores. A obra é composta por duzentos e dez verbetes, possui mais de quarenta ilustrações em preto e branco, fornecendo referências bibliográficas para cada entrada. São, em geral, referências de obras básicas, mas também de obras específicas sobre o assunto, o que contribui para que os leitores mais exigentes ou interessados no tema possam ter acesso a bibliografia de pesquisa, ou até mesmo a poder conferir as fontes usadas (informação não disponível nos dois dicionários brasileiros anteriormente comentados). Nesse sentido, a organização do Dicionário de mitologia nórdica lembra o Norse mythology $\left(2001^{5}\right)$, escrito por John Lindow (UC, Berkeley), atualmente uma autoridade nos

\footnotetext{
${ }^{4}$ SPALDING, Tarsilo Orpheu - Dicionário de Mitologias Européias e Orientais. Rio de Janeiro: Cultrix / MEC, 1973.

${ }^{5}$ LINDOW, John - Norse mythology: a guide to the gods, heroes, rituals and beliefs. New York: Oxford University Press, 2001.
} 
estudos escandinavos medievais. O guia produzido por John Lindow é, ainda hoje, uma referência nos estudos de mitologia nórdica, não só para os iniciados, mas também pela serventia das referências e demais informações disponíveis.

O dicionário de Johnni Langer e o guia têm em comum uma grande quantidade de verbetes, a presença das imagens, várias referências bibliográficas, a tradução de citações e de fontes primárias. Contudo, qualquer comparação não poderá ir além destes aspectos. Pois o guia possui uma introdução mais extensa e um capítulo final onde o autor comenta os estudos vikings e escandinavos. A obra de John Lindow possui ainda um sumário e um índice onomástico. Tais elementos teriam sido de grande utilidade no dicionário brasileiro aqui recenseado. Este, não obstante ter mais de duzentas páginas (indicador do facto de alguns verbetes serem mais detalhados) do que o homólogo de 2001, possui apenas um breve prefácio e introdução e não dispõe nem de sumário, nem de índice onomástico, o que dificulta a localização das entradas e a identificação dos temas tratados e por tratar. À parte estes aspectos de teor mais formal, o conteúdo é sem dúvida de boa qualidade temática e de redacção, espelhando o zelo dos seus autores em concretizar um trabalho satisfatório.

O dicionário disponibiliza dados sobre deuses como Odin, Thor, Freyr e Freyja, e de outras divindades menos conhecidas como Njörd, Heimdall, Frigga, Sif, Iduna, Skadi, Nornas, entre outros. Aborda ainda personagens complexos como Loki e informa acerca de outros seres mitológicos como os anões, elfos, gigantes, dragões, valquírias e alguns monstros. Os verbetes tratam também a cosmogonia e a cosmologia nórdicas designadamente os mitos de criação e dos "Nove Mundos" -, bem como a escatologia representada pelo mito do Ragnarök, associado a uma ideia de “apocalipse nórdico”. A obra contempla igualmente os aspectos religiosos dos nórdicos da Era Viking (VIII-XI), a saber: as concepções sobre alma, espiritualidade, vida após a morte, mundos da morte como o Valhala e Hel; lugares sagrados, sacrifícios de animais e de humanos e oferendas; animais sagrados (lobos, ursos, águias, cavalos e corvos); símbolos sagrados, como o Sol, a Lua, o Valknut, a suástica, o martelo de Thor etc.; alimentos e bebidas sagradas e relatos sobre alguns dos ritos fúnebres dos vikings. 
De referir ainda a consideração da importância do Xamanismo e do Cristianismo na religiosidade nórdica. Neste sentido, há um verbete dedicado à influência de autores cristãos na redação dos mitos, uma vez que as Eddas, as duas principais fontes mitológicas desta cultura, foram escritas no século XIII, época em que a Islândia estava já cristianizada. Trata-se de um aspecto algo controverso que nos leva a colocar a seguinte interrogação: os mitos ali relatados, provenientes da tradição oral, terão sido não apenas influenciados, mas também alterados pelas influências do cristianismo? Outro aspecto importante do dicionário diz respeito às referências sobre a astronomia dos vikings, revelando que tais povos eram conhecedores das estrelas, assim se explicando o facto de serem exímios navegantes. Os verbetes relativos às constelações, astrologia, zodíaco e astronomia foram escritos por Johnni Langer que, nos últimos anos, tem publicado trabalhos de etnoastronomia e de mitologias celestes escandinavas ${ }^{6}$. Dada a importância da magia no quotidiano destes povos, encontram-se verbetes sobre armas e objetos mágicos; runas; encantamentos e plantas e alimentos usados nos ritos mágicos, da autoria de Luciana de Campos (PPGL-UFPB), que possui alguns trabalhos publicados desta temática.

A cultura material, toponímia, geografia, história e a arqueologia da sociedade nórdica também estão presentes. No caso da arqueologia, destacam-se os verbetes sobre as pedras rúnicas (runestones), monumentos que preservaram a escrita rúnica e a pictografia usada pelos escandinavos. Todavia, para um autor não familiarizado com a área, recomendam-se os verbetes sobre a Edda Poética (num conjunto de poemas de autoria anônima) e a Edda em Prosa (autoria atribuída ao poeta Snorri Sturluson), as duas principais fontes literárias sobre a mitologia nórdica, ambas escritas no século XIII, na Islândia.

Há outras fontes mencionadas no dicionário, nomeadamente no verbete sobre Mitologia nórdica, nos poemas escaldos, nas sagas islandesas, nas crônicas e manuscritos avulsos. Tal permite facultar ao leitor as fontes necessárias para conhecer e estudar essa mitologia e a até mesmo a história viking, já que as sagas islandesas, as crônicas e alguns poemas tendem abordar aspectos históricos e não apenas mitológicos, como a

${ }^{6}$ LANGER, Johnni - "Constelações e mitos celestes na Era Viking: reflexões historiográficas e etnoastronômicas”. Roda da Fortuna v. 4, 1 (2015), pp. 107-130.

Medievalista online № 22 | Julho - Dezembro 2017 ๑ IEM - Instituto de Estudos Medievais 5 www2.fcsh.unl.pt/iem/medievalista 
crônica alemã Gesta Hammaburgensis Ecclesiae Pontificum (História dos Arcebispos de Hamburg-Bremen), escrita por Adão de Bremen (c. 1045-1081/1085); a Gesta Danorum (Feitos dos dinamarqueses) redigida no começo do século XIII, pelo historiador conhecido pelo pseudônimo de Saxo Grammaticus, e o Heimskringla (Círculo do mundo), cuja autoria é atribuída a Snorri Sturluson (1178-1241).

Além das referências e do comentário às fontes, o dicionário apresenta a tradução de algumas destas obras, inéditas na língua portuguesa, na medida em que foram feitas a partir do original. Um aspecto digno de relevo, uma vez que as principais fontes mitológicas nórdicas, as Eddas, não possuíam nenhuma tradução para o Português excepção feita para a Edda em $\operatorname{Prosa}^{7}$, traduzida a partir de uma edição inglesa. Assim, destaca-se a tradução levada a cabo por Pablo Gomes Miranda (UFPB/NEVE/VIVARIUM-NE) do poema “Haraldskcði” (“Balada de Haraldr”), atribuído ao poeta Dórbjörn Hornflöki e escrito por volta do século IX. Aqui, o autor refere os guerreiros berserkir, conhecidos pela sua bravura, força e pela ferocidade com que lutavam. Pela mão de Yuri Fabri Venâncio (USP/NEHiLP) encontramos a tradução do poema “Darraðarljóð” (“Canção das Lanças”), de autoria anônima e datado do século XI, cuja história relata a Batalha de Contraf, ocorrida no ano de 1014, próximo de Dublin, na Irlanda. “Thrymskivda” (“A canção de Thrym”) é um dos poemas da Edda Poética, que recebeu tradução integral diretamente do islandês para o português pelo mesmo autor, Yuri Fabi Venâncio, consistindo na única tradução acadêmica brasileira do poema medieval, que narra o roubo do martelo de Thor realizado pelo gigante Thrym. Também as traduções sobre encantamentos mágicos merecem destaque, nomeadamente o “Encantamento das nove ervas” traduzido por Álvaro Bragança Júnior (UFRJ/NIELIM) e Makyo Sotero Medronho e o “Encantamento de Busla” traduzido Johnni Langer. Traduções que trazem pela primeira vez para a língua portuguesa importantes práticas mágicas comuns na cultura germano-escandinava.

O dicionário contempla também a relação da mitologia nórdica com as artes e com a atual cultura pop. Destaca-se a entrada Quadrinhos e Mitos Nórdicos, assinada por Carlos Manoel de Hollanda Cavalcanti (PUC-RJ/UCAM/IED), onde se aborda a

\footnotetext{
${ }^{7}$ STURLUSON, Snorri - Edda em Prosa. Trad. Marcelo Magalhães Lima. Rio de Janeiro: Numen, 1993.
} 
apropriação da mitologia nórdica pela literatura das histórias em quadrinhos (banda desenhada), sendo um dos maiores expoentes o Thor da Marvel Comics. O verbete Wagner e os Mitos Nórdicos, de âmbito musical, é redigido por João Eduardo Lupi (UFSC) e versa as óperas do compositor alemão Richard Wagner, nomeadamente " $\mathrm{O}$ Anel dos Nibelungos”, obra influenciada pela mitológica nórdica. A influência da mitologia escandinava na obra do escritor e professor J. R. R. Tolkien, autor de $O$ Hobbit, O Senhor dos Anéis e de Silmarillion, é tratada por Reinaldo José Lopes (USP), especialista na obra do autor britânico Tolkien ${ }^{8}$.

Como consideração final, pode dizer-se que o Dicionário de mitologia nórdica é uma obra de fácil leitura, mas nem por isso menos rigorosa e acadêmica, já que os mitos referidos não são tratados de modo meramente narrativo, mas com análise de conteúdo. Assim, a obra pode satisfazer não só os leitores que se interessam pela mitologia nórdica por curiosidade, mas também os leitores que pretendem iniciar-se neste campo de estudos, ou mesmo os especializados na área - o Brasil, Portugal e dos demais países de língua lusófona passam a dispor de uma obra em português que cumpre bem qualquer uma destas funções.

\section{COMO CITAR ESTE ARTIGO}

\section{Referência electrónica:}

OLIVEIRA, Leandro Vilar - "Recensão: LANGER, Johnni (org.) - Dicionário de mitologia nórdica: símbolos, mitos e ritos. São Paulo: Hedra, 2015 (581pp.)”. Medievalista 22 (Julho-Dezembro 2017). [Em linha] [Consultado dd.mm.aaaa]. Disponível em http://www2.fcsh.unl.pt/iem/medievalista/MEDIEVALISTA22/oliveira2211.html ISSN 1646-740X.

\footnotetext{
${ }^{8}$ LOPES, Reinaldo José - “With many voices and in many tongues?” Pseudotradução, autorrefração e profundidade cultural na ficção de J.R.R. Tolkien. São Paulo: Faculdade de Filosofia, Letras e Ciências Humanas da Universidade de São Paulo (USP), 2012. Tese de Doutorado.
} 
Recensão / Review • Leandro Vilar Oliveira

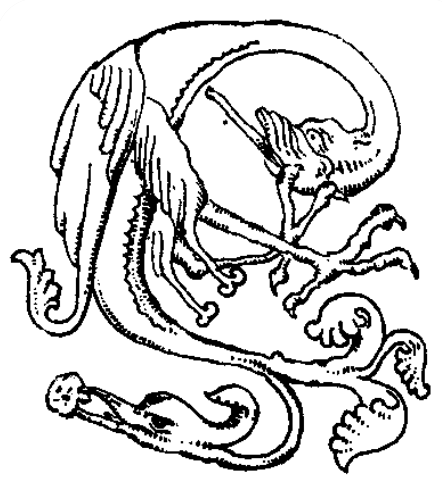

